\title{
Pharmacists' knowledge, attitude and involvement in palliative care in selected tertiary hospitals in southwestern Nigeria
}

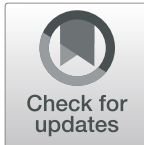

Rasaq ADISA ${ }^{1 *}$ and Aderonke Tolulope ANIFOWOSE ${ }^{2}$

\begin{abstract}
Background: The growing number of people living with life-limiting illness is a global health concern. This study therefore aimed to explore the involvement of pharmacists in selected tertiary hospitals in Nigeria in palliative care (PC). It also sought to evaluate their knowledge and attitude to PC as well as factors that hinder pharmacists' participation in PC.
\end{abstract}

Method: Questionnaire-guided survey among pharmacists working in three-tertiary hospitals in southwestern Nigeria. The self-administered questionnaire comprised 18-item general knowledge questions related to PC, attitude statements with 5-point Likert-scale options and question-items that clarify extent of involvement in PC and barriers to participation. Overall score by pharmacists in the knowledge and attitude domains developed for the purpose of this study was assigned into binary categories of "adequate" and "inadequate" knowledge (score $>75 \%$ versus $\leq 75 \%$ ), as well as "positive" and "negative" attitude (ranked score $>75 \%$ versus $\leq 75 \%$ ), respectively. Descriptive statistics, Mann-Whitney-U and Kruskal-Wallis tests were used for analysis at $p<0.05$.

Results: All the 110 pharmacists enrolled responded to the questionnaire, given a response rate of $100 \%$. Overall, our study showed that 23(21.1\%) had adequate general knowledge in PC, while 14(12.8\%) demonstrated positive attitude, with 45(41.3\%) who enjoyed working in PC. Counselling on therapy adherence (100;90.9\%) was the most frequently engaged activity by pharmacists; attending clinical meetings to advise health team members (45;40.9\%) and giving educational sessions (47;42.7\%) were largely cited as occasionally performed duties, while patient home visit was mostly cited (60;54.5\%) as a duty not done at all. Pharmacists' unawareness of their need in PC (86;79.6\%) was a major factor hindering participation, while pharmacists with PC training significantly felt more relaxed around people receiving PC compared to those without training $(p=0.003)$.

Conclusion: Hospital pharmacists in selected tertiary care institutions demonstrate inadequate knowledge, as well as negative attitude towards PC. Also, extent of involvement in core PC service is generally low, with pharmacists' unawareness of their need in PC constituting a major barrier. Thus, a need for inclusion of PC concept into pharmacy education curriculum, while mandatory professional development programme for pharmacists should also incorporate aspects detailing fundamental principles of $\mathrm{PC}$, in order to bridge the knowledge and practice gaps.

Keywords: Hospital pharmacists, Knowledge, attitude and involvement, Palliative care, Nigeria

\footnotetext{
*Correspondence: adisaras73@yahoo.co.uk; rasaq.adisa@mail.ui.edu.ng

${ }^{1}$ Department of Clinical Pharmacy and Pharmacy Administration, Faculty of

Pharmacy, University of Ibadan, Ibadan, Nigeria

Full list of author information is available at the end of the article
}

(c) The Author(s). 2019 Open Access This article is distributed under the terms of the Creative Commons Attribution 4.0 International License (http://creativecommons.org/licenses/by/4.0/), which permits unrestricted use, distribution, and reproduction in any medium, provided you give appropriate credit to the original author(s) and the source, provide a link to the Creative Commons license, and indicate if changes were made. The Creative Commons Public Domain Dedication waiver (http://creativecommons.org/publicdomain/zero/1.0/) applies to the data made available in this article, unless otherwise stated. 


\section{Background}

The growing number of people living with life-limiting illness is a global health concern that may necessitate a paradigm shift towards provision of palliative care service by all healthcare professionals regardless of the practice settings [1-4]. Current estimate suggests that approximately $75 \%$ of people approaching the end-oflife may benefit from palliative care [4], with international and local evidence demonstrating the impact of palliative care on patient outcomes, caregiver and healthcare [2]. Palliative care is a patient- and familycentred approach to care focusing on quality of life and relief of symptoms [5-7], thus, it is a complex health discipline that requires extensive collaboration and teamwork among healthcare professionals, patients and caregivers $[6,8,9]$. Studies have identified the palliative care population as one of the groups who are at the highest risk of medication misadventure and adverse events, and consequently increased hospital admissions $[10,11]$. Adam et al [12] reported that almost one-third of patients with cancer access out-of-hours primary medical care due to poorly controlled pain. In essence, patients requiring palliative care typically have complicated and high risk medication regimen such as opioids that require frequent adjustment and monitoring [13, 14], thereby making the pharmacist a highly desirable member of palliative care team whose contribution can potentially improve the patient medication management and reduce the risk of non-adherence [15-17]. Published reports especially from developed countries have identified different roles played by pharmacists in palliative care with benefits and effectiveness of service offered in this context [15-23]. However, in most developing countries, palliative care is still an emerging medical specialty that require healthcare providers' contribution and participation [24-27]. In Nigeria for instance, palliative care is in its early stage of development $[9,24,25,27]$, with services mainly limited to patients who attend the tertiary hospitals [24], while pharmacists were recognized among the least considered member of the healthcare team providing palliative care service [27-30]. In addition, the Benchmark for Minimum Academic Standard from the two major regulatory agencies for pharmacy education in Nigeria, that is the National Universities Commission and the Pharmacists Council of Nigeria does not include aspects on palliative care in the curriculum contents. This is in spite of the pharmacists' essential role in medication therapy management especially for patients with complex chronic regimen [15-23]. Nevertheless, studies from developed countries have generally identified reasons for low involvement of pharmacists in palliative care to include inadequate knowledge and skills, deficient education and training in palliative care
$[16,30-32]$, as well as attitude and belief towards palliative care [16, 30, 33]. In Nigeria however, there is dearth of evidence-based research that directly examine the extent of pharmacists' involvement in palliative care as well as barriers to participation. This study therefore aimed to comprehensively evaluate knowledge, attitude and involvement of hospital pharmacists in selected tertiary healthcare institutions in southwestern Nigeria in palliative care, while factors that may hinder their involvement in palliative care were also explored. The information obtained from this study may help in identifying areas of focus for future advocacy and intervention to address the practice gaps.

\section{Method}

\section{Study design}

This study was a questionnaire-guided survey among pharmacists working in three selected tertiary hospitals with established palliative care services between February and April, 2017.

\section{Study setting}

Pharmacy departments of selected hospitals namely University College Hospital (UCH) Ibadan, Obafemi Awolowo University Teaching Hospitals Complex (OAUTH) Ile-Ife and Federal Medical Centre (FMC) Abeokuta. The $\mathrm{UCH}$ is a 900-bed premier teaching hospital in Nigeria, affiliated with University of Ibadan; OAUTHC is a 600-bed teaching hospital affiliated with Obafemi Awolowo University, while FMC is a 350-bed tertiary care hospital established with a special focus on chronic disease management. The hospitals are federal healthcare institutions strategically located within the southwest geopolitical zone in the country, and are major sites for undergraduate and post-graduate residency training for physicians, as well as clinical training for other categories of healthcare practitioners including pharmacists, nurses and other ancillary healthcare personnel.

\section{Study population}

Post-intern pharmacists working in the three selected tertiary hospitals.

\section{Inclusion and exclusion criteria}

Post-intern hospital pharmacists who consented to participate in the study were enrolled, while those with less than 1 year experience in hospital practice were excluded.

\section{Sample size determination}

Number of eligible pharmacists from each hospital was obtained from the respective institution as: $\mathrm{UCH}=70$, $\mathrm{OAUTHC}=38$ and $\mathrm{FMC}=12$, given a total estimated 
population of 120 pharmacists in the three selected facilities. Based on the estimated population at $95 \%$ confidence level and 5\% margin of error, a sample size of 92 was obtained using Yamane sample size formula [34]. Adjusting for a $10 \%$ non-response rate gave a target sample population of approximately 102 . The proportion of pharmacists recruited from each facility was subsequently guided as follows: $\operatorname{UCH}\left(\frac{70}{120} X 102=60\right)$, $\operatorname{OAUTHC}\left(\frac{38}{120} X 102=32\right)$ and $\operatorname{FMC}\left(\frac{12}{120} X 102=10\right)$, where the numerator denotes number of eligible pharmacists in the respective hospital, while the denominator represents the estimated population. The total of 110 copies of questionnaire were given to pharmacists in the three selected hospitals.

\section{Data collection instrument}

The main instrument used for data collection was a semi-structured questionnaire developed by the investigators following extensive review of relevant studies $[6,7,24,30]$, as well as utilizing previous experience from palliative care training. The questionnaire consisted of five sections. Section A captured demographic characteristics, years of experience in hospital practice, previous training in palliative care, as well as cadre/rank. Section B contained 18-item questions that evaluated general knowledge in palliative care. Section $C$ evaluated opinion on relevant attitude-related statements toward palliative care which was adapted from Pitzen (2009) [35]. The attitude questions had a 5-point Likert scale response option ranging from strongly disagree (1) to strongly agree (5) for positive statements (1-6), and a reversed score for the negative statements $(7-13)$. Section D contained item-statements that clarified extent of involvement in some palliative care services in their respective practice site, while Section E contained questions that explored possible factors that may hinder involvement in palliative care (see additional file 1).

\section{Pretest and content validation}

The questionnaire was assessed for content validity by two pharmacists in academia chosen from the department of Clinical Pharmacy and Pharmacy Administration, University of Ibadan, to ascertain the comprehensiveness of question-items vis-à-vis the study objectives, as well as ensuring that there are no ambiguous questions or statements. Subsequently, the questionnaire was given to three pharmacists chosen from a state-owned specialist hospital notable for chronic disease management, to ascertain the ease of comprehension of the item-statements. Feedback from the pretest and content validation led to few modifications in the questionnaire such as rephrasing of a dichotomous Yes/No response option as a "true" or "false" answer for questions on general knowledge in palliative care. Also, the re-designing of attitude statements from a Yes/No answer into a Likert scale response option to ensure clarification of opinion.

\section{Sampling and data collection procedure}

Eligible hospital pharmacists were enrolled using purposive sampling approach by visiting individual pharmacist in their respective practice site. Objectives of the study were explained to every pharmacist after which voluntary verbal informed consent was obtained to signify intention to participate in the study. The questionnaire was self-administered by all consented pharmacists and retrieved within 25-30 min of completion of the questionnaire. Anonymity and confidentiality of response were assured, while participation was entirely voluntary.

\section{Data analysis}

Data obtained were sorted, coded and entered into Microsoft Excel spreadsheet file for ease of data management, and subsequently the computed data were exported into SPSS version 21.0 for analysis. Descriptive statistics including frequency and percentage were used to summarise the data. In this study, the overall score by pharmacists in the knowledge and attitude domains developed for the purpose of this study was converted into percentage to ensure uniformity in the scores. In the knowledge domain, a total score $>75 \%$ was considered as "adequate" knowledge, while score $\leq 75 \%$ signified "inadequate" knowledge. In other word, a percent score $>75 \%$ indicates a raw score of $>13$ out of the 18 questions that evaluated the general knowledge in palliative care; $>6$ out of 8 questions on knowledge of diseases that mostly require palliative care service; and $>5$ out of 7 questions on knowledge of palliative care team composition. In the attitude domain, a total ranked score $>75 \%$ was considered as "positive" attitude, that is, a raw score of $\geq 49$ out of maximum obtainable score of 65 , while a ranked score $\leq 75 \%$ signified "negative" attitude towards palliative care. The cut-off criteria for the binary categorization was adapted from Bloom's cut-off point criteria, as well as review of other related studies $[36,37]$. Pearson Chi-square $\left(\mathrm{X}^{2}\right)$ test was used to investigate association between demographic characteristics, as well as years of experience in hospital practice and general knowledge in palliative care. Mann-Whitney U (MWU) test was used to evaluate association among pharmacists with or without palliative care training and opinion on attitude-related statements, while relationship between hospital of practice by pharmacists and attitude towards palliative care was investigated using Kruskal-Wallis $(\mathrm{K}-\mathrm{W})$ test at $p<0.05$ level of statistical significance. 


\section{Results}

All the 110 pharmacists who were enrolled responded to the questionnaire, given a response rate of $100 \%$. Fiftyeight (52.7\%) pharmacists participated from $\mathrm{UCH}, 37$ (33.6\%) from OAUTHC and 15 (13.6\%) from FMC. Details of demographic characteristics and years of experience in hospital practice are shown in Fig. 1. The majority, $72(65.5 \%)$ were in the age range of $20-40$ years, 58 (52.7\%) were females and 35 (32.7\%) had additional postgraduate qualification. Participants (46; 41.8\%) were mostly in the pharmacist grade one cadre (i.e. within 1 to 3 years of full-time hospital employment). Seventy-seven (58.8\%) of the pharmacists had worked in the general outpatient pharmacy unit within the last 2 years prior to the commencement of this study, $16(12.2 \%)$ in ward pharmacy unit, $10(7.6 \%)$ in medical outpatient, $8(6.1 \%)$ in oncology, $6(4.6 \%)$ in paediatric unit, $5(3.8 \%)$ in virology, $3(2.3 \%)$ in surgical outpatient, $2(1.5 \%)$ in haematology and immunology, 2 $(1.5 \%)$ in radiopharmacy/nuclear pharmacy, while one $(0.8 \%)$ each had worked in psychiatry and as a member of palliative care team. Eighty-three (75.7\%) had encountered patients requiring palliative care, while 21 (19.1\%) had previously attended a palliative care related training.

Table 1 shows the general knowledge of pharmacists in palliative care. Ninety-one $(85.0 \%)$ understood that long-time use of opioids for palliative care patients does not often results in addiction. One hundred and one (93.5\%) felt that the goals of palliative care are consistent with the philosophy of pharmaceutical care, while $67(64.2 \%)$ had a misconception that medication therapy is the cornerstone of all symptom control in palliative care. Overall, 23 (21.1\%) had score $>75 \%$ indicating "adequate" knowledge of palliative care and its principles (see Table 1). Table 2 provides information on the knowledge of pharmacists in relation to palliative care team composition, as well as diseases that mostly require palliative care service. Sixty-five (59.1\%) were absolutely correct in citing all the listed categories of professionals as a possible member of palliative care team (see Table 2).

Response of pharmacists to attitude-related statements is shown in Table 3. Forty-five (41.3\%) enjoyed working in palliative care, $61(57.0 \%)$ felt confident in managing symptoms in palliative care, while 90 (83.3\%) believed that it is rewarding to work with people receiving palliative care. A total of 14 (12.8\%) demonstrated "positive" attitude towards palliative care (see Table 3). Table 4 shows the perceived extent of pharmacists' involvement in general patient and palliative care services. Counselling on therapy adherence (100; 90.9\%), as well as ensuring complete labelling and direction for medication usage $(100 ; 90.9 \%)$ were the most frequently engaged activities. Giving educational sessions (47; 42.7\%) and attending clinical meetings to advise other health team members $(45 ; 40.9 \%)$ were largely cited as occasionally performed duties, while patient home visit was mostly cited $(60 ; 54.5 \%)$ as a duty not done at all (see Table 4). Perceived factors limiting involvement in palliative care are shown in Table 5. Pharmacists' unawareness of their need in palliative care $(86 ; 79.6 \%)$ topped the list of factors hindering participation, while non-accessibility to patients' medication profile (72; $70.6 \%$ ), inadequate knowledge of palliative care among

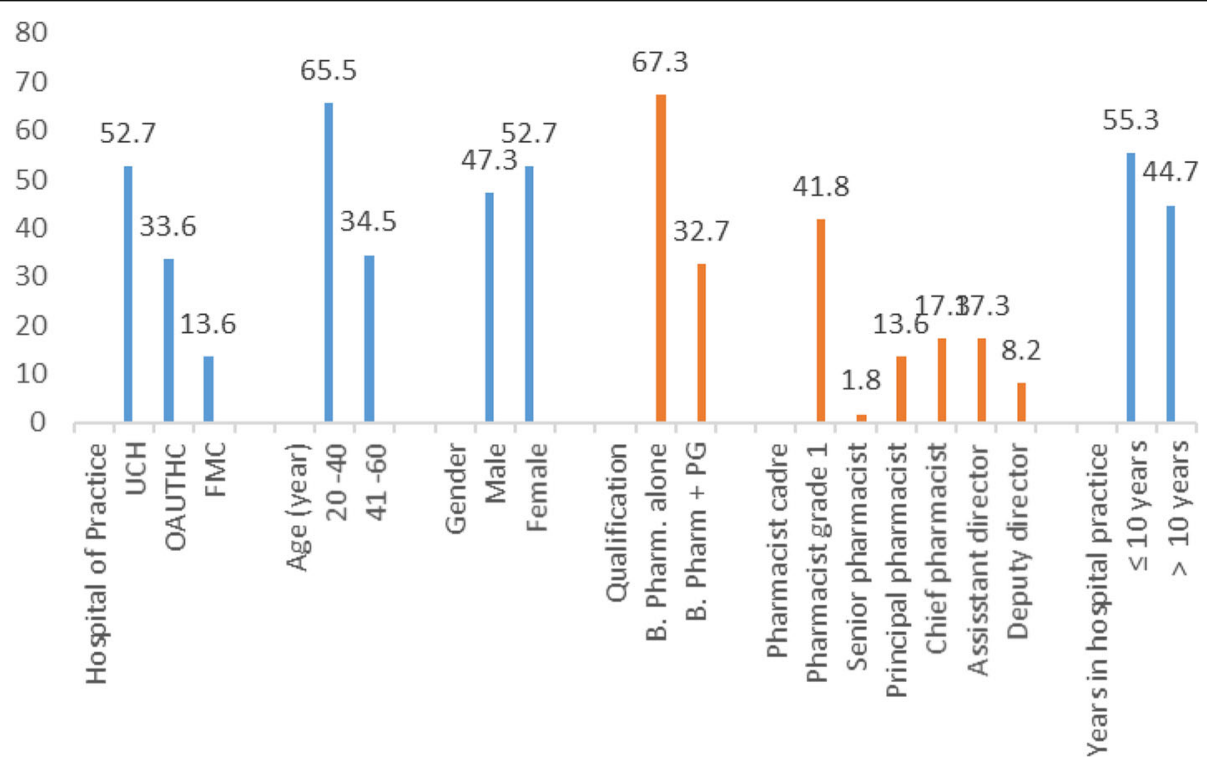

Fig. 1 Demographic characteristics and years of experience in hospital practice among pharmacists (Demographic variables versus percent) 
Table 1 Response to the 18-items general knowledge questions about palliative care and its principles among pharmacists

\begin{tabular}{|c|c|c|}
\hline Statement & True, n (\%) & False, n (\%) \\
\hline $\begin{array}{l}\text { 1.Palliative care involves provision of care only to patients who have no curative treatment } \\
\text { available }(n=108)\end{array}$ & $43(39.8)$ & $65(60.2)^{a}$ \\
\hline 2. Non-medical practitioners are active participant in palliative care $(n=108)$ & $63(58.3)^{\mathrm{a}}$ & $45(41.7)$ \\
\hline 3. Palliative care is to be provided by doctors and nurses alone $(n=109)$ & $3(2.8)$ & $106(97.2)^{a}$ \\
\hline 4. Palliative care is required only for patients who are near death $(n=108)$ & $18(16.7)$ & $90(83.3)^{a}$ \\
\hline 5. Palliative care only involves pain management $(n=108)$ & $25(23.1)$ & $83(76.9)^{a}$ \\
\hline 6. Palliative care involves providing patients with relief from their symptoms $(n=109)$ & $66(60.6)^{\mathrm{a}}$ & $43(39.4)$ \\
\hline $\begin{array}{l}\text { 7. Regular opioids intake should not be combined with non-steroidal anti-inflammatory drugs for } \\
\text { palliative care patients }(n=99)\end{array}$ & $45(45.5)$ & $54(54.5)^{a}$ \\
\hline 8. Long term use of opioids for palliative care patients does not often induce addiction ( $n=107$ ) & $91(85.0)^{\mathrm{a}}$ & $16(15.0)$ \\
\hline 9. Palliative care should not be provided alongside anti-retroviral treatment $(n=99)$ & $5(5.1)$ & $94(94.9)^{a}$ \\
\hline 10. One of the goals of pain management in palliative care is to get good night sleep ( $n=108$ ) & $14(13.0)^{\mathrm{a}}$ & $94(87.0)$ \\
\hline 11. Benzodiazepines should be effective for controlling delirium in palliative care patients ( $n=93$ ) & $71(76.3)^{a}$ & $22(23.7)$ \\
\hline 12. Palliative care does not involve maintaining patient medication profile overtime $(n=105)$ & $8(7.6)$ & $97(92.4)^{\mathrm{a}}$ \\
\hline $\begin{array}{l}\text { 13. Palliative care should not be provided in conjunction with curative care at the time of diagnosis } \\
\text { of a potential life-limiting illness }(n=101)\end{array}$ & $14(13.9)$ & $87(86.1)^{\mathrm{a}}$ \\
\hline 14. The goals of palliative care and pharmaceutical care are consistent $(n=108)$ & $101(93.5)^{a}$ & $7(6.5)$ \\
\hline 15. Medication therapy is the cornerstone of all symptom control in palliative care $(n=104)$ & $67(64.4)$ & $37(35.6)^{*}$ \\
\hline $\begin{array}{l}\text { 16. Involvement in palliative care activities by pharmacists may decrease the need for medical } \\
\text { emergencies }(n=103)\end{array}$ & $103(100.0)^{\mathrm{a}}$ & $0(0.0)$ \\
\hline $\begin{array}{l}\text { 17. Pharmacist in palliative care should be less concerned about monitoring non-prescription } \\
\text { medication use for safety and effectiveness }(n=107)\end{array}$ & $3(2.8)$ & $104(97.2)^{a}$ \\
\hline $\begin{array}{l}\text { 18. Pharmacists in palliative care communicate with pharmaceutical manufacturers to determine the } \\
\text { availability of nonstandard dosage forms }(n=99)\end{array}$ & $61(61.6)^{a}$ & $38(38.4)$ \\
\hline Cut-off for overall percent score & n (\%) & Remark \\
\hline$>75$ & $23(21.1)$ & Adequate \\
\hline$\leq 75$ & $86(78.9)$ & Inadequate \\
\hline
\end{tabular}

$\mathrm{a}=$ Correct answer. Maximum obtainable score $=18 ; \%$ individual score $=$ score obtained by an individual $\div$ total obtainable score $\times 100, n=$ number

pharmacists $(65 ; 60.2 \%)$, as well as fear of being around people with terminal illness (32; 29.9\%) were also cited as barriers (see Table 5).

Table 6 shows relationship among pharmacists with or without palliative care training and opinion on attitude-related statements. Pharmacists who had training in palliative care were mostly found to be familiar with pain symptoms in palliative care (Mean rank $[\mathrm{MR}]=69.24$ ) compared to $\mathrm{MR}$ of 47.59 among those without training $[\mathrm{MWU}=499.000$, two-tailed $p$ value $=$ 0.002] (see Table 6).

Hospital of practice by pharmacists significantly influenced their opinion on some attitude-related statements toward palliative care such as level of confidence in managing symptoms in palliative care, MR for FMC > OAUTHC > UCH $\left[\mathrm{K}-\mathrm{WX}^{2}=7.016, \mathrm{df}=2\right.$, two-tailed $\mathrm{p}$ value $=0.03]$ (see Table 7). Also, statement related to the extent of familiarity with pain symptoms in palliative care significantly differed among pharmacists from different practice sites, MR for FMC $>$ OAUTHC $>\mathrm{UCH}$
$\left(\mathrm{K}-\mathrm{WX}^{2}=7.241, \mathrm{df}=2\right.$, two-tailed $\mathrm{p}$ value $\left.=0.03\right)$. Years of experience in hospital practice, $1-10$ versus $>10$ years (Pearson $\mathrm{X}^{2}=0.261, \mathrm{df}=1$, two-sided $p=0.609$ ), previous attendance in palliative care training or not $\left(\mathrm{X}^{2}=\right.$ $0.108, \mathrm{df}=1, p=0.74)$, gender $\left(\mathrm{X}^{2}=0.563 ; \mathrm{df}=1, p=\right.$ $0.453)$ and hospital of practice by pharmacists $\left(\mathrm{X}^{2}=1.89\right.$, $\mathrm{df}=2, p=0.388)$ did not significantly influenced pharmacists' general knowledge in palliative care.

\section{Discussion}

In this study, we comprehensively evaluated the knowledge, attitude and involvement of hospital pharmacists in selected tertiary care institutions in Nigeria in palliative care, while factors that may hinder their participation in palliative care were also explored. Notably, a response rate of $100 \%$ was recorded which may possibly be an indication that the research area for our study might be of interest to the participants. However, $78.9 \%$ of the pharmacists had inadequate general knowledge of palliative care, with almost two-thirds who had a 
Table 2 Pharmacists' knowledge of diseases requiring palliative care and palliative care team composition

\begin{tabular}{|c|c|c|}
\hline \multirow{2}{*}{$\begin{array}{l}\text { Variables }(n=110) \\
\text { Disease requiring palliative care service }\end{array}$} & \multicolumn{2}{|c|}{ Response category } \\
\hline & Yes, n (\%) & No, n (\%) \\
\hline Cardiovascular diseases & $60(54.5)^{\mathrm{a}}$ & $50(45.5)$ \\
\hline HIV/AIDS & $95(86.4)^{\mathrm{a}}$ & 15 (13.6) \\
\hline Renal diseases & $83(75.5)^{\mathrm{a}}$ & $27(24.5)$ \\
\hline Peptic ulcer diseases & $24(21.8)$ & $86(78.2)^{a}$ \\
\hline Asthma & $32(29.1)$ & $78(70.9)^{\mathrm{a}}$ \\
\hline End stage pulmonary diseases & $90(81.8)^{a}$ & $20(18.2)$ \\
\hline Parkinson disease & $62(56.4)^{a}$ & $48(43.6)$ \\
\hline Dementia & $62(56.4)^{\mathrm{a}}$ & $48(43.6)$ \\
\hline Cut-off for overall percent score & Frequency (\%) & Remark \\
\hline$>75$ & $21(19.1)$ & Adequate knowledge \\
\hline$\leq 75$ & $89(80.9)$ & Inadequate knowledge \\
\hline Palliative care team composition includes: & Yes, n (\%) & No, n (\%) \\
\hline Physician & $107(97.3)$ & $3(2.7)$ \\
\hline Pharmacist & $107(97.3)$ & $3(2.7)$ \\
\hline Nurse & $105(95.5)$ & $5(4.5)$ \\
\hline Psychologist & $94(85.5)$ & $16(14.5)$ \\
\hline Chaplain & $75(68.2)$ & $35(31.8)$ \\
\hline Social worker & $90(81.8)$ & $20(18.2)$ \\
\hline All of the above & $65(59.1)^{b}$ & $45(40.9)$ \\
\hline Cut-off for overall percent score & Frequency (\%) & Remark \\
\hline$>75$ & $73(66.4)$ & Adequate knowledge \\
\hline$\leq 75$ & 37 (33.6) & Inadequate knowledge \\
\hline
\end{tabular}

${ }^{a}$ Correct answer, ${ }^{b}=$ most correct answer, $\mathrm{n}=$ number, maximum obtainable score for questions on knowledge of diseases requiring palliative care $=8$, and palliative care team composition $=7 ; \%$ individual score $=$ score obtained by an individual $\div$ total obtainable score $\times 100$. Cancer is excluded as a response option because it is well-known that patients with cancer will require palliative care

misconception that medication therapy is the cornerstone of all symptom control in palliative care. More than $90 \%$ identified the goals of palliative care to be consistent with the philosophy of pharmaceutical care, while all recognized the fact that pharmacists' involvement in palliative care may decrease the need for medical emergencies. O'Connor et al [30] in the Australian nationwide survey reported that community pharmacists' participant in their study had good knowledge of some aspects of palliative care but misconception about others. Some studies from developed countries have also identified low level of knowledge of palliative care among pharmacists [14-16, 38]. However, perusing the response of our study participants to the knowledge questions gave highlights on the areas of strength and common misconception about palliative care, thereby indicating the possible aspects to focus for educational programme and future intervention to address the knowledge gaps among the pharmacists.

It is worthy of note to mention that less than onefifth of the pharmacists had previous training in palliative care, with less than $1 \%$ who reported to have worked as a member of palliative care team, but more than three-quarters had encountered patients requiring palliative care service. This perhaps underscore the need to further encourage pharmacists generally and hospital pharmacists in particular to engage in palliative care related training, in order to ensure effective contribution in palliative care. Previous studies have identified the importance of palliative care training in improving the knowledge of pharmacists, as well as facilitating their involvement in providing services for palliative care patients [21, 30]. Pharmacists' participation as a member of palliative care team can potentially improve patient medication management knowledge, as well as reduce the risk of non-adherence $[14,15,38]$. Studies especially in developed countries have identified and reported pharmacists' positive contributions in palliative care [15, 18-21, 39].

Overall, approximately one-eighth demonstrate positive attitude towards palliative care, with slightly more than half who felt confident in managing symptoms in patients receiving palliative care, while $41.3 \%$ enjoy working in palliative care. Research indicates that many 
Table 3 Assessment of pharmacists' attitude towards palliative care

\begin{tabular}{|c|c|c|c|c|c|}
\hline Attitude statement related to palliative care & $\begin{array}{l}\mathrm{SD}(1) \\
\mathrm{n}(\%)\end{array}$ & $\begin{array}{l}D(2) \\
n(\%)\end{array}$ & $\begin{array}{l}U(3) \\
\mathrm{n}(\%)\end{array}$ & $\begin{array}{l}\text { A (4) } \\
\text { n (\%) }\end{array}$ & $\begin{array}{l}\text { SA (5) } \\
\mathrm{n}(\%)\end{array}$ \\
\hline 1.I enjoy working in palliative care $(n=109)$ & $\begin{array}{l}16 \\
(14.7)\end{array}$ & $\begin{array}{l}40 \\
(36.7)\end{array}$ & $8(7.3)$ & $\begin{array}{l}32 \\
(29.4)\end{array}$ & $\begin{array}{l}13 \\
(11.9)\end{array}$ \\
\hline 2. I feel relaxed around people receiving palliative care $(n=105)$ & $5(4.8)$ & $9(8.6)$ & $\begin{array}{l}48 \\
(45.7)\end{array}$ & $\begin{array}{l}36 \\
(34.3)\end{array}$ & $7(6.7)$ \\
\hline 3. I feel confident in managing symptoms in palliative care $(n=106)$ & $1(0.9)$ & $9(8.5)$ & $\begin{array}{l}35 \\
(33.0)\end{array}$ & $\begin{array}{l}52 \\
(49.1)\end{array}$ & $9(8.5)$ \\
\hline 4. I feel comfortable talking about dying to a patient receiving palliative care $(n=105)$ & $\begin{array}{l}19 \\
(18.1)\end{array}$ & $\begin{array}{l}39 \\
(37.1)\end{array}$ & $\begin{array}{l}34 \\
(32.4)\end{array}$ & $10(9.5)$ & $3(2.9)$ \\
\hline $\begin{array}{l}\text { 5. I don't mind working in palliative care despite its involvement in managing people with } \\
\text { life-limiting illness }(n=108)\end{array}$ & $4(3.7)$ & $\begin{array}{l}12 \\
(11.1)\end{array}$ & $\begin{array}{l}58 \\
(53.7)\end{array}$ & $\begin{array}{l}25 \\
(23.1)\end{array}$ & $9(8.3)$ \\
\hline 6. There is a difference between providing palliative care service and normal hospital care $(n=108)$ & $\begin{array}{l}35 \\
(32.4)\end{array}$ & $\begin{array}{l}54 \\
(50.0)\end{array}$ & $10(9.3)$ & $7(6.5)$ & $2(1.9)$ \\
\hline & SD (5) & $\mathrm{D}(4)$ & U (3) & A (2) & SA (1) \\
\hline 7. I am not comfortable touching people with terminal illness $(n=107)$ & $\begin{array}{l}31 \\
(29.0)\end{array}$ & $\begin{array}{l}51 \\
(47.7)\end{array}$ & $\begin{array}{l}18 \\
(16.8)\end{array}$ & $6(5.6)$ & $1(0.9)$ \\
\hline $\begin{array}{l}\text { 8. I don't believe that pharmacists have any role to play as a member of palliative care team ( } n= \\
\text { 108) }\end{array}$ & $\begin{array}{l}68 \\
(62.9)\end{array}$ & $\begin{array}{l}29 \\
(26.9)\end{array}$ & $8(7.4)$ & $1(0.9)$ & $2(1.9)$ \\
\hline 9. I feel frustrated because I do not know how to help people receiving palliative care ( $n=107$ ) & $\begin{array}{l}21 \\
(19.6)\end{array}$ & $\begin{array}{l}53 \\
(49.5)\end{array}$ & $\begin{array}{l}25 \\
(23.4)\end{array}$ & $8(7.5)$ & $0(0.0)$ \\
\hline 10. It is not rewarding to work with people who are receiving palliative care $(n=108)$ & $\begin{array}{l}39 \\
(36.1)\end{array}$ & $\begin{array}{l}51 \\
(47.2)\end{array}$ & $\begin{array}{l}11 \\
(10.2)\end{array}$ & $4(3.7)$ & $3(2.8)$ \\
\hline 11. I am not familiar with pain symptoms necessary for palliative care $(n=105)$ & $7(6.7)$ & $\begin{array}{l}43 \\
(41.0)\end{array}$ & $\begin{array}{l}18 \\
(17.1)\end{array}$ & $\begin{array}{l}33 \\
(31.4)\end{array}$ & $4(3.8)$ \\
\hline 12. Working with terminally ill patients is sad and depressing $(n=107)$ & $7(6.5)$ & $\begin{array}{l}26 \\
(24.3)\end{array}$ & $\begin{array}{l}22 \\
(20.6)\end{array}$ & $\begin{array}{l}41 \\
(38.3)\end{array}$ & $\begin{array}{l}11 \\
(10.3)\end{array}$ \\
\hline 13. Emotionally I don't fit into palliative care $(n=103)$ & $\begin{array}{l}18 \\
(17.5)\end{array}$ & $\begin{array}{l}42 \\
(40.8)\end{array}$ & $\begin{array}{l}32 \\
(31.1)\end{array}$ & $7(6.8)$ & $4(3.8)$ \\
\hline Cut-off for overall percent attitude score & \multicolumn{2}{|c|}{ Frequency (\%) } & \multicolumn{3}{|l|}{ Remark } \\
\hline$>75$ & \multicolumn{2}{|c|}{$14(12.8)$} & \multicolumn{3}{|c|}{ Positive attitude } \\
\hline$\leq 75$ & \multicolumn{2}{|c|}{$95(87.2)$} & \multicolumn{3}{|c|}{ Negative attitude } \\
\hline
\end{tabular}

Maximum obtainable score $=65 ; \%$ individual score $=$ score obtained by an individual $\div$ total obtainable score $\times 100$. Statements 1 to 6 are positive attitude items, and 7 to 13 are negative attitude items. Strongly disagree (SD), Disagree (D), Undecided (U), Agree (A), Strongly agree (SA), $n=$ number

healthcare professionals especially in developing countries are poorly prepared for the complexities of palliative care $[21,28,29,33]$, with the key factors influencing involvement mentioned to include confidence issues, inadequate knowledge and skills as well as attitude, belief and experience $[16,19,30,33]$. Thus, any palliative care educational programme or training to be designed for pharmacists should largely focus on building knowledge as well as fostering positive attitude and belief about palliative care [30], as this may help to increase involvement in palliative care services [40, 41]. Belief, support and knowledge have been reported as predictors of pharmacists' overall positive attitude towards palliative care [30]. One measure to ensure increase in pharmacists' knowledge and attitude about palliative care, especially in resource-poor countries may partly involve incorporation of palliative care concept into the curriculum of undergraduate and postgraduate pharmacy education, while the mandatory continuous professional development programme for practicing pharmacists should also include aspects detailing the fundamental principles of palliative care.

In this study, around a third of pharmacists reported that they are comfortable working in palliative care, with only about one-eighth who felt at ease talking about dying to patients receiving palliative care. The multifaceted nature of palliative care require professionals working with patients having life-limiting illness to possess the ability to address psychosocial needs [42, 43], through effective communication skills [21]. Healthcare providers including pharmacists therefore need to develop excellence in communication skills that will assist in clarifying the psychological and social needs of the patients so as to consistently ensure better therapeutic outcomes.

Nearly half of the pharmacists agreed with the statement that indicates that it is sad and depressing working with terminally ill patients. Even though it 
Table 4 Pharmacists' perceived extent of involvement in general patient care and palliative care services

\begin{tabular}{|c|c|c|c|c|}
\hline My involvement in patient care as a pharmacist entails: & $\begin{array}{l}\text { Not at all } \\
\mathrm{n}(\%)\end{array}$ & $\begin{array}{l}\text { Rarely } \\
\mathrm{n}(\%)\end{array}$ & Occasionally n (\%) & Frequently $n(\%)$ \\
\hline 1.Explain misconceptions about addictive medication $(n=110)$ & $7(6.4)$ & $18(16.4)$ & $37(33.6)$ & $48(43.6)$ \\
\hline $\begin{array}{l}\text { 2. Visit patients' homes to communicate directly with patients and their caregivers } \\
\text { and to make necessary assessments }(n=110)\end{array}$ & $60(54.5)$ & $36(32.7)$ & $11(10.0)$ & $3(2.7)$ \\
\hline 3. Monitor patients' medication profile for safety and effectiveness ( $n=109$ ) & $2(1.8)$ & $31(28.4)$ & $33(30.3)$ & $43(39.4)$ \\
\hline $\begin{array}{l}\text { 4. Provide patients with essential medications that ensure continuous symptom } \\
\text { control }(n=110)\end{array}$ & $14(12.7)$ & $6(5.5)$ & $15(13.6)$ & $75(68.2)$ \\
\hline $\begin{array}{l}\text { 5. Attend clinical meetings to advise other members of healthcare team about } \\
\text { medication therapy }(n=110)\end{array}$ & $12(10.9)$ & $22(20.0)$ & $45(40.9)$ & $31(28.2)$ \\
\hline $\begin{array}{l}\text { 6. Advise clinical team on dosage forms and adjustments, routes of administration, } \\
\text { costs, and availability of various drug products }(n=110)\end{array}$ & 15 (13.6) & $13(11.8)$ & $42(38.2)$ & $40(36.4)$ \\
\hline 7. Give educational sessions $(n=110)$ & $15(13.6)$ & $23(20.9)$ & $47(42.7)$ & $25(22.7)$ \\
\hline $\begin{array}{l}\text { 8. Advise members of the clinical team about the potential for toxicity and interactions } \\
\text { with dietary supplements and alternative therapies }(n=110)\end{array}$ & $13(11.8)$ & $34(30.9)$ & $37(33.6)$ & $26(23.6)$ \\
\hline $\begin{array}{l}\text { 9. Ensure that all medication labeling is complete and understandable by patients and } \\
\text { their caregivers }(n=110)\end{array}$ & $4(3.6)$ & $4(3.6)$ & $2(1.8)$ & $100(90.9)$ \\
\hline $\begin{array}{l}\text { 10. Communicate with patients about the importance of adhering to the prescribed } \\
\text { drug regimen }(n=110)\end{array}$ & $0(0.0)$ & $4(3.6)$ & $6(5.5)$ & $100(90.9)$ \\
\hline 11. Monitor all prescription and nonprescription medication use $(n=108)$ & $3(2.8)$ & $7(6.5)$ & $38(35.2)$ & $60(55.5)$ \\
\hline $\begin{array}{l}\text { 12. Counsel patients about potential toxicity of alternative and complementary } \\
\text { therapies }(n=109)\end{array}$ & $2(1.8)$ & $9(8.3)$ & $35(32.1)$ & $63(57.8)$ \\
\hline $\begin{array}{l}\text { 13. Extemporaneous preparation of non-conventional dosage forms for ease of } \\
\text { administration to patients }(n=109)\end{array}$ & $4(3.7)$ & $5(4.6)$ & $28(25.7)$ & $72(66.1)$ \\
\hline 14. Prepare flavouring medications to promote compliance $(n=103)$ & $5(4.9)$ & $16(15.5)$ & $40(38.8)$ & $42(40.8)$ \\
\hline 15. Address issues on cost of patients' medications $(n=110)$ & $6(5.5)$ & $12(10.9)$ & $43(39.1)$ & $49(44.5)$ \\
\hline $\begin{array}{l}\text { 16. Ensure that drug disposal is in compliance with federal and state drug control } \\
\text { and environmental protection laws and regulations }(n=103)\end{array}$ & $3(2.9)$ & $16(15.5)$ & $26(25.2)$ & $58(56.3)$ \\
\hline
\end{tabular}

$n$ Number

Table 5 Perceived factors limiting pharmacists' involvement in palliative care

\begin{tabular}{|c|c|c|c|}
\hline General factors & Yes, n (\%) & No, n (\%) & Don't know, n (\%) \\
\hline Lack of awareness of the need for pharmacists in palliative care $(n=108)$ & $86(79.6)$ & $17(15.7)$ & $5(4.6)$ \\
\hline Lack of access to patients' medication profile $(n=102)$ & $72(70.6)$ & $21(20.6)$ & $9(8.8)$ \\
\hline Inadequate knowledge of palliative care among pharmacists $(n=108)$ & $65(60.2)$ & $29(26.9)$ & $14(13.0)$ \\
\hline Confusion of role in palliative care $(n=106)$ & $62(58.5)$ & $30(28.3)$ & $14(13.2)$ \\
\hline Inadequate knowledge of concept of palliative care $(n=107)$ & $60(56.1)$ & $37(34.6)$ & $10(9.3)$ \\
\hline Lack of reimbursement $(n=109)$ & $48(44.0)$ & $39(35.8)$ & $22(20.2)$ \\
\hline Lack of pharmacists' interest to work in palliative care $(n=107)$ & $45(42.1)$ & $45(42.1)$ & $17(15.9)$ \\
\hline Fear of being around people with terminal illness $(n=107)$ & $32(29.9)$ & $49(45.8)$ & $26(24.3)$ \\
\hline Belief that there could be a spiritual backlash from engaging in palliative care $(n=105)$ & $15(14.3)$ & $67(63.8)$ & $23(21.9)$ \\
\hline Other suggested factors & Frequency & Percent & \\
\hline Rivalry among healthcare workers & 4 & 3.6 & \\
\hline Non-inclusion of palliative care in pharmacists' routine rotations & 2 & 1.8 & \\
\hline Inadequate professional work environment & 1 & 0.9 & \\
\hline
\end{tabular}


Table 6 Association among pharmacists with or without palliative care training and attitude-related statements toward palliative care

\begin{tabular}{|c|c|c|c|c|}
\hline & $\begin{array}{l}\text { Previous } \\
\text { training }\end{array}$ & N & $\begin{array}{l}\text { Mean } \\
\text { Rank }\end{array}$ & $\begin{array}{l}\text { MW Up- } \\
\text { value }\end{array}$ \\
\hline \multirow[t]{2}{*}{ 1.I enjoy working in palliative care } & Yes & 21 & 30.79 & \\
\hline & No & 85 & 59.11 & $<0.001^{*}$ \\
\hline \multirow[t]{2}{*}{ 2. I feel relaxed around people receiving palliative care } & Yes & 21 & 67.57 & \\
\hline & No & 81 & 47.33 & $0.003^{*}$ \\
\hline \multirow[t]{2}{*}{ 3. I feel confident in managing symptoms in palliative care } & Yes & 21 & 58.12 & \\
\hline & No & 83 & 51.08 & 0.299 \\
\hline \multirow[t]{2}{*}{ 4. I feel comfortable talking about dying to a patient receiving palliative care } & Yes & 21 & 58.36 & \\
\hline & No & 82 & 50.37 & 0.251 \\
\hline \multirow{2}{*}{$\begin{array}{l}\text { 5. I don't mind working in palliative care despite its involvement in managing people with life- } \\
\text { limiting illness }\end{array}$} & Yes & 21 & 56.45 & \\
\hline & No & 84 & 52.14 & 0.525 \\
\hline \multirow[t]{2}{*}{ 6. There is a difference between providing palliative care service and normal hospital care } & Yes & 21 & 49.40 & \\
\hline & No & 85 & 54.51 & 0.457 \\
\hline \multirow[t]{2}{*}{ 7. I am not comfortable touching people with terminal illness } & Yes & 21 & 57.76 & \\
\hline & No & 83 & 51.17 & 0.335 \\
\hline \multirow[t]{2}{*}{ 8. I don't believe that pharmacists have any role to play as a member of palliative care team } & Yes & 21 & 53.12 & \\
\hline & No & 85 & 53.59 & 0.940 \\
\hline \multirow[t]{2}{*}{ 9. I feel frustrated because I do not know how to help people receiving palliative care } & Yes & 21 & 58.10 & \\
\hline & No & 83 & 51.08 & 0.303 \\
\hline \multirow[t]{2}{*}{ 10. It is not rewarding to work with people who are receiving palliative care } & Yes & 21 & 56.86 & \\
\hline & No & 84 & 52.04 & 0.481 \\
\hline \multirow[t]{2}{*}{ 11. I am not familiar with pain symptoms necessary for palliative care } & Yes & 21 & 69.24 & \\
\hline & No & 82 & 47.59 & $0.002^{*}$ \\
\hline \multirow[t]{2}{*}{ 12. Working with terminally ill patients is sad and depressing } & Yes & 21 & 58.76 & \\
\hline & No & 83 & 50.92 & 0.267 \\
\hline \multirow[t]{2}{*}{ 13. Emotionally I don't fit into palliative care } & Yes & 20 & 55.88 & \\
\hline & No & 81 & 49.80 & 0.391 \\
\hline
\end{tabular}

$N$ Number, ${ }^{*}$ Significant difference with Mann Whitney U (MWU) test. Higher mean rank for positive statements (1-6) indicate those who mostly agreed with the corresponding statement, while higher mean rank for negative statements (7-13) suggest those who least agreed with the corresponding statement, level of statistical significance $p<0.05$

may be expected that managing patients with lifelimiting illness especially at the end of life can be emotionally draining $[2,5,6]$, palliative care providers should not allow his/her emotion to affect the therapeutic relationship with the patients, thus the need to develop appropriate communication skills and approach to handle the psychosocial aspect of care. Palliative care is an approach to care that emphasize the relief of patients from all forms of suffering and pain including physical, psychological, social, as well as spiritual discomfort [2, 6-8]. In addition to possessing effective communication skills by the pharmacists, clinical experience especially in pain management and symptom control is equally important. Joranson and Gilson [44] report on the influence of pharmacists' knowledge and attitude to opioid pain medications and concluded that incorrect knowledge and inappropriate attitude could lead to errors in the service provided for palliative care patients. Interestingly, in our study, pharmacists who had training in palliative care were largely found to be familiar with pain symptoms in palliative care compared to those without training. Studies have reported improved confidence and positive effects especially in pain and symptom management among healthcare professionals after attendance of post-qualification courses and educational intervention in palliative care $[15,16,45-47]$. Therefore, exposing the future and practicing pharmacists to the core principles of palliative care may perhaps instill the confidence and other needed skills to effectively serve as a competent member of palliative care team. However, to ensure effective palliative care service 
Table 7 Association between pharmacists' hospital of practice and attitude-related statements toward palliative care

\begin{tabular}{|c|c|c|c|c|}
\hline Statement & $\begin{array}{l}\text { Hospital of } \\
\text { practice }\end{array}$ & N & $\begin{array}{l}\text { Mean } \\
\text { Rank }\end{array}$ & $\begin{array}{l}\text { K-Wp- } \\
\text { value }\end{array}$ \\
\hline \multirow[t]{3}{*}{ 1.I enjoy working in palliative care } & FMC & 15 & 54.33 & \multirow[t]{3}{*}{0.996} \\
\hline & OAUTHC & 36 & 55.10 & \\
\hline & $\mathrm{UCH}$ & 58 & 55.11 & \\
\hline \multirow[t]{3}{*}{ 2. I feel relaxed around people receiving palliative care } & FMC & 15 & 61.87 & \multirow[t]{3}{*}{0.42} \\
\hline & OAUTHC & 35 & 51.06 & \\
\hline & $\mathrm{UCH}$ & 55 & 51.82 & \\
\hline \multirow[t]{3}{*}{ 3. I feel confident in managing symptoms in palliative care } & FMC & 15 & 71.93 & \multirow[t]{3}{*}{$0.03^{*}$} \\
\hline & OAUTHC & 35 & 52.57 & \\
\hline & $\mathrm{UCH}$ & 57 & 50.16 & \\
\hline \multirow[t]{3}{*}{ 4. I feel comfortable talking about dying to a patient receiving palliative care } & FMC & 15 & 53.17 & \multirow[t]{3}{*}{0.37} \\
\hline & OAUTHC & 34 & 58.50 & \\
\hline & $\mathrm{UCH}$ & 56 & 49.62 & \\
\hline \multirow{3}{*}{$\begin{array}{l}\text { 5. I don't mind working in palliative care despite its involvement in managing people with life- } \\
\text { limiting illness }\end{array}$} & FMC & 15 & 69.20 & \multirow[t]{3}{*}{$0.02^{*}$} \\
\hline & OAUTHC & 35 & 58.83 & \\
\hline & $\mathrm{UCH}$ & 58 & 48.09 & \\
\hline \multirow[t]{3}{*}{ 6. There is a difference between providing palliative care service and normal hospital care } & FMC & 15 & 46.57 & \multirow[t]{3}{*}{0.49} \\
\hline & OAUTHC & 35 & 57.04 & \\
\hline & $\mathrm{UCH}$ & 58 & 55.02 & \\
\hline \multirow[t]{3}{*}{ 7. I am not comfortable touching people with terminal illness } & FMC & 15 & 64.73 & \multirow[t]{3}{*}{0.18} \\
\hline & OAUTHC & 36 & 48.47 & \\
\hline & $\mathrm{UCH}$ & 56 & 54.68 & \\
\hline \multirow[t]{3}{*}{ 8. I don't believe that pharmacists have any role to play as a member of palliative care team } & FMC & 15 & 61.57 & \multirow[t]{3}{*}{0.43} \\
\hline & OAUTHC & 35 & 50.94 & \\
\hline & $\mathrm{UCH}$ & 58 & 54.82 & \\
\hline \multirow[t]{3}{*}{ 9. I feel frustrated because I do not know how to help people receiving palliative care } & FMC & 15 & 63.43 & \multirow[t]{3}{*}{0.35} \\
\hline & OAUTHC & 35 & 54.31 & \\
\hline & $\mathrm{UCH}$ & 57 & 51.32 & \\
\hline \multirow[t]{3}{*}{ 10. It is not rewarding to work with people who are receiving palliative care } & FMC & 15 & 54.37 & \multirow[t]{3}{*}{0.88} \\
\hline & OAUTHC & 35 & 56.47 & \\
\hline & $\mathrm{UCH}$ & 58 & 51.32 & \\
\hline \multirow[t]{3}{*}{ 11. I am not familiar with pain symptoms necessary for palliative care } & FMC & 14 & 66.43 & \multirow[t]{3}{*}{$0.03^{*}$} \\
\hline & OAUTHC & 35 & 58.31 & \\
\hline & $\mathrm{UCH}$ & 58 & 46.32 & \\
\hline \multirow[t]{3}{*}{ 12. Working with terminally ill patients is sad and depressing } & FMC & 14 & 65.29 & \multirow[t]{3}{*}{0.27} \\
\hline & OAUTHC & 35 & 58.31 & \\
\hline & $\mathrm{UCH}$ & 58 & 46.32 & \\
\hline \multirow[t]{3}{*}{ 13. Emotionally I don't fit into palliative care } & FMC & 15 & 59.57 & \multirow[t]{3}{*}{0.31} \\
\hline & OAUTHC & 33 & 54.73 & \\
\hline & $\mathrm{UCH}$ & 55 & 48.27 & \\
\hline
\end{tabular}


that will improve the quality of care for patients, palliative care educational programme and training should encompass comprehensive pain management techniques including assessment, dose conversion, and counselling especially to allay fear of addiction associated with opioids, as well as development of treatment plans in accordance with accepted standards $[13,14]$.

More than $90 \%$ each of the pharmacists cited counselling on therapy adherence as well as ensuring complete labelling and direction for medication usage as the most frequently engaged activities, while attending clinical meetings and providing educational sessions for other members of healthcare team were mentioned as occasionally performed duties. Patient home visit was topmost of the duties not done at all. Pharmacists' occasional engagement in some of the core practice roles that may propel team-based care possibly suggests the need to also focus palliative care educational programme and training on aspects that will encourage and facilitate collaboration with other healthcare team. Delivery of excellent palliative care requires collaborative input of physicians, pharmacists, nurses and psychosocial careers in a holistic framework, thereby fostering increased confidence with improved quality of care to patients $[48,49]$. The low level of pharmacists' involvement in patient home visit as reflected in our study may also be an issue that need to be improved upon if pharmacists intend to be actively involved in the provision of palliative care service. This is largely because the care for people with life-limiting illness especially in the final year of life is increasingly being moved from hospital to the home [50]. Home-based care has been reported as the most common setting where approximately 70 to $80 \%$ of terminally ill patients prefer to receive care [51].

Topmost of the perceived factors limiting involvement of pharmacists in palliative care was reported as pharmacists' unawareness of their need in palliative care, while lack of access to patients' medication profile, as well as inadequate knowledge of palliative care were also mentioned as barriers. Limited access to patients' medical records has been generally reported as one of the major factors hindering pharmacists' proactive engagement in patient-centred care such as palliative care [18, 52]. However, confidence issues [18] as well as inadequate knowledge and skills necessary for delivering effective palliative care service $[16,30$, 33] remains a paramount gap that need to be addressed among pharmacists generally, and hospital pharmacists in particular on account of their strategic role in healthcare delivery. Contrary to what may be obtained in most developed countries [18-20,53], in Nigeria, patients who require palliative care mostly attend tertiary care hospitals [24], thereby encounter hospital pharmacists more often than those in other practice areas. Therefore, efforts should be geared towards ensuring increase in knowledge and skills of hospital pharmacists in medical ethics, pain management, as well as symptom control with excellence in communication skills [43, 54]. This can be partly achieved through a focused and targeted educational and training programme towards the areas of deficiencies and needs among the pharmacists.

In this study, opinion on some attitude-related statements significantly differ among pharmacists from the three hospitals, especially in relation to the level of confidence in managing symptoms in palliative care, as well as flair for involvement in palliative care services. In Nigeria, palliative care is an emerging specialty, thus, healthcare professionals in each hospital may possibly be at different stages of palliative care involvement and implementation. The American Society of Health System Pharmacists has stated that the extent of service rendered by pharmacists may differ based on practice experience as well as the level of palliative care services in the respective setting [16].

Though, this study provides useful information about hospital pharmacists' knowledge, attitude and involvement in palliative care, its limitation may include the small sample size, though representative of the pharmacists' population in the studied hospitals. Also, only content validity and pretest of the study instrument were done rather than subjecting the questionnaire to all the validation checks typically require for a healthrelated patient reported outcome [55], thus, there may be possibility of bias with some questions or statements. Nevertheless, this study focused largely on hospital pharmacists' knowledge, attitude and involvement in palliative care, thus, the rigorous validation checks may not be strictly essential [55]. Moreover, the itemstatements in the questionnaire for our study covers a wide-range of aspects in palliative care which may partly allow for a comprehensive exploration of participants on the subject area, hence, a useful strength for our study. Another limitation may be linked to the fact that, our study was carried out in tertiary hospitals with established palliative care services, thus the need for caution in generalising the findings to the entire population of hospital pharmacists in the region.

\section{Conclusion}

It can be concluded from this study that hospital pharmacists in selected tertiary care institutions demonstrate inadequate general knowledge, as well as negative attitude towards palliative care. Also, their involvement in core palliative care service is generally low, with pharmacists' unawareness of their need in 
palliative care constituting a major barrier. This perhaps suggest a need for inclusion of palliative care concept into the pharmacy education curriculum, while mandatory continuous professional development programme for practicing pharmacists should also incorporate aspects detailing fundamental principles of palliative care, in order to bridge the knowledge and practice gaps.

\section{Supplementary information}

Supplementary information accompanies this paper at https://doi.org/10. 1186/s12904-019-0492-8

Additional file 1. Questionnaire for the study.

\section{Abbreviations}

EC: Ethics committee; FMC: Federal Medical Centre; K-W: Kruskal Wallis; MR: Mean rank; MWU: Mann-Whitney-U; OAUTHC: Obafemi Awolowo University Teaching Hospitals Complex; PC: Palliative care; SPSS: Statistical package for social sciences; UCH: University College Hospital; UI: University of Ibadan

\section{Acknowledgements}

The authors acknowledge all consented pharmacists who volunteered to be part of the study.

\section{Authors' contributions}

RA designed the study, conduct the statistical analysis, developed the manuscript and completed the final write up of the manuscript. ATA was involved in the design of the study, collection of data and draft of the manuscript. Both authors read, revised and approved the paper before its final submission.

\section{Authors' information}

Rasaq Adisa is a Ph. D holder, Senior Lecturer and the current Head of Department, Clinical Pharmacy and Pharmacy Administration, Faculty of Pharmacy, University of Ibadan, Ibadan, Nigeria.

Aderonke Tolulope Anifowoshe is the Head of Pharmacy unit, University Health Service, University of Ibadan and a post-graduate student in the Department of Clinical Pharmacy and Pharmacy Administration, Faculty of Pharmacy, University of Ibadan, Nigeria.

\section{Funding}

No fund or support was received in carrying out this study.

\section{Availability of data and materials}

The datasets used and/or analysed during the current study are available from the corresponding author on reasonable request.

\section{Ethics approval and consent to participate}

Ethics approval for the study was obtained from the University of Ibadan/ University College Hospital Ethics Review Committee with approval number UI/EC/16/0378. Permission was also obtained from the Head of Pharmacy department of the respective hospital. Verbal informed consent in accordance with the approved study protocol by the Ethics committee, was obtained from individual participant after explaining the objectives and procedure of the study to participant individually. The study is strictly a questionnaire-based survey with questions carefully designed without infringement on patient's privacy, while the questionnaire was duly translated into the local language of the patients for proper comprehension. Only the consented participants within the study period were enrolled.

\section{Consent for publication}

Not applicable.

\section{Competing interests}

The authors declare that they have no competing interests.

\section{Author details}

'Department of Clinical Pharmacy and Pharmacy Administration, Faculty of Pharmacy, University of Ibadan, Ibadan, Nigeria. ${ }^{2}$ University Health Services, University of Ibadan, Ibadan, Nigeria.

Received: 24 July 2019 Accepted: 20 November 2019

Published online: 29 November 2019

\section{References}

1. Agora. Palliative care in the Neitherlands 2014. http://www-agora.nl/ zorgkiezen/statistieken. Accessed 10 July 2019.

2. Chan KS. Palliative care: the need of the modern era. Hong Kong Med J. 2018;24:391-9.

3. Rodriquez A. Global need for palliative care and pain relief. Am J Manag Care. 2017; http://www.ajmc.com Accessed 10 July 2019.

4. Etkind SN, Bone AE, Games B, Lovell N, Evans CJ, Higginson JJ, Murtaght FEM. How many people will need palliative care in 2040? Past trends, future projections and implications for services. BMC Med. 2017;15:102. https://doi. org/10.1186/s12916-017-0860-2.

5. Guo Q, Jacelon CS, Marquard JL. An evolutionary concept analysis of palliative care. J Palliat Care Med. 2012;2:1-6.

6. Center to Advance Palliative Care, (CAPC). Defining palliative care. New York: CAPC; 2013. http://www.capc.org/building-a-hospital-based-palliative-careprogram/case/definingpc. Accessed 20 Feb 2019

7. World Health Organisation (WHO). WHO definition of palliative care 2011. http://www.who.int/cancer/palliative/definition/en/ Accessed 10 July, 2019.

8. Smith TJ, Coyne PJ, Cassel JB. Practical guidelines for developing new palliative care services: resource management. Ann Oncol. 2012;23(Suppl 3): 70-5.

9. Soyannwo OA. Palliative care and nursing. Afr J Med Med Sci. 2009;38(Suppl 2):67-70

10. Mathers $C D$, Loncor D. Projections of global mortality and burden of disease from 2012 to 2030. PLoS Med. 2006:3:2011-30.

11. World Health Organisation. Projections of mortality and causes of death, 2015 and 2030. http://www.who.int/healthinfor/global-burden-disease/ projection/en/ Accessed 10 July 2019

12. Adam R, Wassell P, Murchie P. Why do patients with cancer access out-ofhours primary care? A retrospective study. Br J Gen Pract. 2014;64:e99-104.

13. Craig DS. Introduction: pharmacist role in pain management. J Pharm Pract. 2012;25:496.

14. Barbee J, Chessher J, Greenlee M. Pain Management: the Pharmacist's evolving role. Pharm Times. 2015; http://www.pharmacytimes.com/ publications/health-system-edition/2015/july2015/pain-management-thepharmacists-evolving-role Accessed 20 Feb 2019.

15. Hussainy S, Box M, Scholes S. Piloting the role of a pharmacist in a community palliative care multidisciplinary team: an Australian experience. BMC Palliat Care. 2011;10:16. https://doi.org/10.1186/1472-684X-10-16.

16. Hussain SY, Marriot IL, Beattie J, Nation RL, Dooley MJ. A palliative cancer care flexible education program for Australian community pharmacists. Am J Pharm Educ. 2010;74:1-9.

17. American Society of Health-System Pharmacists (ASHP). ASHP statement on the pharmacist's role in hospice and palliative care. Am J Health Syst Pharm. 2002:59:1770-3.

18. Needham DS, Wong IC, Campion PD. Hull, east riding pharmacy development $\mathrm{G}$. evaluation of the effectiveness of UK community pharmacists' interventions in community palliative care. Palliat Med. 2002; 16(3):219-25.

19. Edwards Z, Blenkinsopp AB, Ml. A community pharmacist medicines optimisation service for patients with advanced cancer pain: a proof of concept study. Int J Clin Pharm. 2019;41:700-10

20. Savage IAB, Bennett M. Community pharmacists' contributions to the management of cancer pain in the community. BMJ Support Palliat Care. 2011;1(A6). https://doi.org/10.1136/bmjspicare-2011-00002004.

21. O'Connor M, Fisher C, French L, Halkett G, Jiwa M, Hughes J. Exploring the community pharmacist's role in palliative care: focusing on the person not just the prescription. Patient Educ Couns. 2011:83:458-64.

22. Atayee RS, Best BM, Daniels CE. Development of an ambulatory palliative care pharmacist practice. J Palliat Med. 2008;11(8):1077-82.

23. Jiwa M, Hughes J, O'Connor M, Tuffin P. Field testing a protocol to facilitate the involvement of pharmacists in community based palliative care. Aust Pharm. 2012;31(1):72-6. 
24. Fadare JO, Obimakinde AM, Olaogun DO, Afolayan JM, Olatunya O, Ogundipe KO. Perception of nurses about palliative Care: experience from south-West Nigeria. Ann Med Health Sci Res. 2014;4(5):723-7.

25. Harding R, Higginson IJ. Palliative care in sub-Saharan Africa. Lancet. 2005; 365:1971-7.

26. Smith AK, Thai JN, Bakitas MA, Meier DE, Spragens LH, Temel JS, Weissman DE, Rabow MW. The diverse landscape of palliative care clinics. J Palliat Med. 2013;16:661-8.

27. Onyeka TC. Palliative care in Enugu, Nigeria: challenges to a new practice. Indian J Palliat Care. 2011;17(2):131-6.

28. Farber NJ, Urban SY, Colllier VU, Metzger M, Weiner J, Boyer EG. Frequency and perceived competence in providing palliative care to terminally ill patients: a survey of primary care physicians. J Pain Symptom Manag. 2004; 28:364-72.

29. O'Connor M, Pugh J, Jiwa M, Hughes J, Fisher C. The palliative care interdisciplinary team: where is the community pharmacist? J Palliat Med. 2011;14:7-11.

30. O'Connor M, Hewitt LY, Tuffin PHR. Community pharmacists attitude toward palliative Care. An Australian Nationwide survey. J Palliat Med. 2013;16: 1575-81.

31. Ise Y, Morita T, Maehori N, Kutsuwa M, Shiokawa M, Kizawa Y. Role of the community pharmacy in palliative care: a nationwide survey in Japan. J Palliat Med. 2010;13:733-7.

32. Akram G, Bennie M, McKellar S, Michels S, Hudson S, Trundle J. Effective delivery of pharmaceutical palliative care: challenges in the community pharmacy setting. J Palliat Med. 2012;15:317-21.

33. Ahmed N, Bestall JC, Ahmedzai SH, Payne SA, Clark D, Noble B. Systematic review of the problems and issues of accessing specialist palliative care by patients careers and health and social care professionals. Palliat Med. 2004; 18:525-42.

34. Yamane T. Statistics, an introductory analysis, vol. 886. 2nd ed. New York: Harper and Rao; 1967.

35. Pitzen KM. Occupational therapy and palliative care: a survey of attitudes and knowledge (scholarly project). Ohio: Department of Occupational Therapy, University of Toledo Digital Repository, Toledo; 2009.

36. Abdullahi A, Hassan A, Kadarnman N, Saleh A, Baraya YS. Lua PL food safety knowledge, attitude and practice toward compliance with abattoir laws among the abbatoir workers in Malaysia. Int J Gen Med. 2016;9:79-87.

37. Hahida A. Knowledge, attitude and practice of denque fever prevention among people in male Maldives. Thailand: Published Masters Dissertation. Chulalongkorn, University; 2007.

38. Ingleton C, Gardiner C, Seymour JE, Richards N, Gott M. Exploring education and training needs among the palliative care workforce. BMJ Support Palliat Care. 2013;3:207-12

39. Gilbar $P$, Stefaniuk K. The role of the pharmacists in palliative care: results of a survey conducted in Australia and Canada. J Palliat Care. 2002;18:287-92.

40. McClement SE, Care D, Dean R, Cheang M. Evaluation of education in palliative care: determining the effects on nurses' knowledge and attitudes. J Palliat Care. 2005;21:44-8

41. McDonald N, Boston W, Scott JF. The Canadian palliative care undergraduate curriculum. J Cancer Educ. 1993;8:197-201.

42. Nelson JE. Identifying and overcoming the barriers to high quality palliative care in the intensive care unit. Crit Care Med. 2016:34:320-31.

43. McDonough RP. Intervention to improve patient pharmaceutical care outcomes. J Am Pharm Assoc (Wash). 1996;NS36:453-66.

44. Joranson DE, Gilson AM. Pharmacists' knowledge of and attitudes toward opioid pain medications in relation to federal and state policies. J Am Pharm Assoc. 2001;41:213-20.

45. Adriaansen MJ, van Achterberg T, Borm G. Effects of a post-qualification course in palliative care. J Adv Nurs. 2005;49:96-103.

46. Shipman C, Burt J, Ream E, Beynon T, Richardson A, Addington-Hall J. Improving district nurses' confidence and knowledge in the principles and practice of palliative care. J Adv Nurs. 2008;63:494-505.

47. Hansen L, Goodell TT, Dehaven J, Smith M. Nurses' perceptions of end-oflife care after multiple interventions for improvement. Am J Crit Care. 2009; 18:263-71

48. Center to Advance Palliative Care (CAPC). Improving Care for People with Serious IIIness through Innovative Payer-Provider Partnerships, 2015. http:// www.capc.org. Accessed 20 Feb 2019.
49. Forbes JF. Toward an optimal teaching programme for supportive care. Support Care Cancer. 1994:2:7-15.

50. Department of Health. A health future for Western Australians: report of the health reform committee Perth. Western Australia: Department of Health: 2004

51. Lynn J. Serving patients who may die soon and their families: the role of hospice and other services. J Am Med Assoc. 2001;285:925-32.

52. Gibbs M. In: Cherny N, Fallon M, Kaasa S, DC PRKC, editors. The contribution of the clinical pharmacist in palliative care in. Oxford textbook of palliative medicine. 5th ed. London: Oxford University Press; 2015.

53. Savage I, Blenkinsopp A, Closs SJ, Bennett MI. 'Like doing a jigsaw with half the parts missing': community pharmacists and the management of cancer pain in the community. Inter J Pharm Pract. 2013;21(3):151-60.

54. Hill RR. Clinical pharmacy services in a home-based palliative care program. Am J Health Syst Pharm. 2007:64:806-10.

55. Mokkink LB, Terwee CB, Stratford PN, Alonso J, Patrick DL, Bouter LM. The COSMIN checklist for evaluating the methodological quality of studies on measurement properties: a clarification of its content. BMC Med Res Methodol. 2010;10:22. https://doi.org/10.1186/1471-2288-10-22.

\section{Publisher's Note}

Springer Nature remains neutral with regard to jurisdictional claims in published maps and institutional affiliations.
Ready to submit your research? Choose BMC and benefit from:

- fast, convenient online submission

- thorough peer review by experienced researchers in your field

- rapid publication on acceptance

- support for research data, including large and complex data types

- gold Open Access which fosters wider collaboration and increased citations

- maximum visibility for your research: over $100 \mathrm{M}$ website views per year

At BMC, research is always in progress.

Learn more biomedcentral.com/submissions 